\title{
AGRICULTURA TRADICIONAL E OS SISTEMAS ECONÔMICOS QUILOMBOLAS DE JUÇARAL DOS PRETOS - PRESIDENTE JUSCELINO-MA
}

\author{
TRADITIONAL AGRICULTURE AND THE QUILOMBOLA ECONOMIC \\ SYSTEMS OF JUÇARAL DOS PRETOS - PRESIDENT JUSCELINO-MA
}

\author{
Jackson Bouéres Damasceno Júnior ${ }^{1}$ \\ https://orcid.org/0000-0002-3381-5295 \\ http://lattes.cnpq.br/7678671370933584
}

\section{Marivania Leonor Sousa Furtado² \\ http://lattes.cnpq.br/3275591203804166 \\ https://orcid.org/0000-0002-2140-304X}

Recebido em: 26 de abril de 2020

Aprovado em: 11 de julho de 2020

RESUMO: O desenvolvimento possui distintos significados, variando entre o recurso a ser explorado para a sobrevivência ou para o acúmulo de capital de seus possuidores. No caso específico das comunidades tradicionais, a exploração dos recursos naturais pelos quilombolas acontece de maneira harmônica, respeitando os limites impostos pela natureza. Atualmente, esse tipo de exploração constitui um potencial para o desenvolvimento rural. O grande diferencial é que os sistemas autóctones de produção de alimentos são caracterizados por serem limpos de agroquímicos, fator muito apreciado pela sociedade urbana atualmente. A relação econômica entre sociedade e natureza também é respeitosa, sendo evidenciada pelas práticas de comercialização pouco impactantes e que permitem a sua replicação, favorecendo, nesse caso específico, a discussão do conceito de moderno e atrasado. Por meio da reconstrução de sistemas agrários e da metodologia da observação participante, esta pesquisa buscou compreender as relações entre as comunidades tradicionais e a natureza e de que forma a renda monetária é produzida, considerando os impactos criados durante essa criação. Ademais, não se perdem de vista as relações sociais baseadas em práticas culturalmente construídas, que são mais fortes do que a produção com objetivos comerciais.

Palavras-chave: Desenvolvimento rural. Agricultura sustentável. Comercialização da produção.

\footnotetext{
${ }^{1}$ Observatório de Desenvolvimento Sócio Espacial/Universidade Estadual do Maranhão. Engenheiro Agrônomo, mestre em agroecologia, doutor em desenvolvimento rural. Docente formador do curso de licenciatura intercultural indígena da Universidade Estadual do Maranhão. E-mail: jbagroeco@gmail.com.

2 Professora adjunta da Universidade Estadual do Maranhão, membro do corpo permanente do programa de Pós-Graduação em Desenvolvimento Socioespacial e Regional. Coordena a Licenciatura Intercultural para a Educação Básica Indígena/UEMA. Coordenadora do Grupo de Estudos, Pesquisa e extensão em Lutas Sociais, Igualdade e DiversidadesLIDA/UEMA. Cientista Social pela UFMA (1995) com Mestrado em Sociologia pela Universidade Federal do Ceará (2001) e Doutorado em Geografia pela Universidade Estadual Paulista - Campus Presidente Prudente (2012). E-mail: marivaniafurtado@yahoo.com.br.
} 


\begin{abstract}
Knowledge has different meanings, ranging from the resource to be exploited for a victory to the capital accumulation of its owners. In the specific case of meals, the constitution of a quilombo is not present. The big difference is that indigenous food production systems are characterized by being clean of agrochemicals, as well as the urban nature today. The relation is there is not possible, the evidence is not relevant to them, the evidence of the impact of the mind and the attention of the error. Through the reconstruction of systems and participant observation methodology, this research sought to understand the relationship between customs and nature and the form of income. based on culturally constructed practices that is stronger than production with commercial.
\end{abstract}

Keywords: Rural development. Sustainable agriculture. Marketing ofproduction.

\title{
INTRODUÇÃO
}

A terra é o meio de produção que garante ao seu possuidor simultaneamente poder econômico e político, fazendo com que todas as relações sociais desenvolvidas, sejam locais, regionais, nacionais e internacionais, girem em torno desse fator, constituindo-se como foco constante de tensões. Esse fato é responsável pelo formato da sociedade brasileira, que constitui um interessante mosaico de culturas marcado por apartaides étnicos e sociais significativos, os quais são evidenciados historicamente, tendo na pilhagem dos recursos naturais seu alicerce central.

Essa realidade começa a amealhar-se ainda com a observação do modelo Brasil colônia, que segundo Holanda, Eulálio e Ribeiro (1995), se constituiu por meio de três componentes fundamentais na organização social, quais sejam: a grande propriedade fundiária, a monocultura de exportação e o trabalho escravo. Dessa maneira, o trabalho era de propriedade dos detentores dos meios de produção e se baseava em apenas mais uma forma de acúmulo de capital financeiro, que servia unicamente para o usufruto dos senhores e de seus herdeiros.

A leitura clássica da gênese da sociedade brasileira trata dos processos simbólicos e desiguais constituintes das relações de produção no país e que se agravaram com o passar dos séculos. Segundo Sousa (2009), algumas barreiras que resultaram desses processos são instransponíveis. Em consequência, o destino da atual sociedade prevê um Estado brasileiro fadado a eternizar-se como produtor de matérias-primas e produtos agrícolas in natura.

Um ponto que deve ser observado quando esses processos são discutidos é que, por mais que nessas etapas tenham sido geradas externalidades negativas e sentimentos de tristeza e dor, muitas foram as belezas criadas e que emanaram das referidas práticas. Afinal, qual o verdadeiro sentido em entender e diferenciar sistemas de produção de alimentos e outros produtos primários?

Algumas vantagens comparativas entre os sistemas tradicionais de produção, que não possuíam grande apelo comercial, começam a ser observadas. Esses processos produzem uma quantidade mínima de rejeitos e toxicidades, tornando-os adequados às temáticas da modernidade, vinculadas a uma vida mais saudável, principalmente por não produzirem rejeitos. Com isso, esses processos estão incluídos entre as atividades "sustentáveis".

Essa leitura inicial remete ao tema da ruralidade, observando que o mesmo não pode ser tratado sem que se recorra metodologicamente à história da ocupação do território, suas for- 
mas de resistência, produção e de organização social, bem como sua relação direta com o ambiente natural no qual está inserido. Essa relação foi estudada por Mazoyer e Roudart (2010), que refletem sobre a complexa relação entre os elementos que estão sobre a terra, a sua ocupação e posterior desenvolvimento.

Neste trabalho, busca-se fazer uma leitura atualizada dos processos agrários estudados por Brumer e Santos (2006), e inserir alguns elementos mais contemporâneos, que pouco têm influenciado pesquisadores e elaboradores de políticas públicas voltadas ao desenvolvimento rural. Tais aspectos remetem a processos de luta, resistência e resiliência social, motivados principalmente pela necessidade de sobrevivência e manutenção de padrões culturais construídos.

Em termos metodológicos, a obtenção dos dados empíricos ocorreu por meio da observação participante junto à comunidade quilombola de Juçaral dos Pretos, localizada no município de Presidente Juscelino, no estado do Maranhão, de onde vieram os dados que foram tabulados e interpretados nesta pesquisa.

Nessa perspectiva, vê-se que a vocação do Brasil como país do futuro ficou no passado, uma vez que se abriu mão do potencial de produção limpa de alimentos e de energia. Logo, o país figura, mais uma vez, entre os campeões mundiais de desmatamento e uso de agrotóxicos.

\section{ABORDANDO A TEORIA DOS MEIOS DE VIDA TRADICIONAIS}

As intervenções no meio rural com foco no desenvolvimento sempre foram baseadas na deslegitimação dos sistemas produtivos desenvolvidos pelas sociedades tradicionais, já que o fundamento principal é o aumento da produtividade. Esse aumento não inclui uma preocupação com a preservação dos recursos naturais, com o uso de tecnologias baseadas em seus padrões culturais e em sistemas econômicos autóctones, fundamentais para a continuidade da vida.

Nesse contexto, as comunidades tradicionais apresentam-se como empecilho ao modelo de exploração convencional, pois essas comunidades têm na satisfação de suas necessidades básicas os parâmetros para a exploração dos recursos naturais. Tais parâmetros são desenvolvidos ao longo do processo de fixação em seus territórios, não tendo como orientação principal a extração de mais valia, formatando modelos próprios de desenvolvimento de práticas econômicas capitalistas.

No caso específico do quilombo de Juçaral dos Pretos, a questão fundiária encontra-se equacionada, pois esses camponeses estão alocados em uma "terra de preto". Nesse caso, o título de propriedade está registrado em nome da comunidade feito pelo antigo senhor de escravos, não sendo registrados conflitos, pois o uso da terra é comum a todos que necessitam viver e produzir.

Ao longo dos anos, sistemas de produção sustentáveis foram desenvolvidos com intuito de gerar renda e satisfazer as necessidades específicas da sociedade local. Esses objetivos estavam em consonância direta com as potencialidades naturais, dando origem a uma forma própria de relacionamento dessa sociedade com o meio em questão e ao seu meio de vida, cujo principal fundamento é a utilização racional da natureza viva.

Para Domingues Garcia (2001), por razões socioeconômicas e ecológicas, uma economia agrícola não pode estar centrada em um ou em poucos produtos. As razões socioeconômicas dizem respeito às crises decorrentes da competitividade internacional, que alteram enorme- 
mente as possibilidades comerciais de um produto e colocam em risco a segurança alimentar. As razões ecológicas estão ligadas à própria região em si, onde deve haver a necessidade do desenvolvimento de técnicas agrícolas diversas.

Uma abordagem sistêmica também deve ser utilizada para contemplar todas as variáveis apresentadas no contexto das sociedades rurais, pois o desenvolvimento é fruto direto desse processo complexo.

Morin (2004) observa a necessidade de perceber o contexto para que as intervenções possam ser positivas, sem fazer com que uma variável venha a se sobressair sobre as outras, permitindo que seja evidenciado o caráter sistêmico. Perondi (2007), por sua vez, observa que a abordagem dos meios de vida (livelihoods) é uma ferramenta analítica que está sendo utilizada com maior ênfase nos estudos sobre pobreza rural no mundo. Essa abordagem apresenta uma grande efetividade na explicação do modo como as pessoas fazem para sobreviver em situações de risco ou em meio às crises ambientais, sociais e econômicas.

Para Ellis (2000, p. 4), a diversificação é um processo social e econômico que traduz a criação de muitas e diferentes fontes de renda em um determinado período de tempo. Nesse ínterim, "um aspecto distintivo da diversificação na maior parte dos países pobres". Esses meios de vida devem funcionar como elemento chave para a continuidade dos padrões sociais e as atividades econômicas tradicionais devem ser tratadas como partes fundamentais de um sistema complexo, próprio de cada sociedade. Esse reconhecimento garante a permanência das outras atividades fundamentais.

Caso esses parâmetros não sejam observados, Sodré et al. (2008) colocam que o rápido declínio dos recursos naturais, indispensáveis à sobrevivência humana, também produz efeitos negativos nas áreas social, ambiental e econômica. O resultado pode ser a substituição automática dos meios de vida tradicionais, o que pode gerar passivos sociais difíceis de serem equacionados.

Segundo Haan e Zoomers (2005), muitos dos estudos sobre espaço doméstico que apareceram a partir dos anos 1980, eram, em sua maioria, conduzidos pelo princípio de que as "novas economias domésticas" deveriam ser focadas na alocação da terra e do trabalho, assim como nas estratégias de renda. Essas novas economias usavam como ferramenta explicativa o modelo microeconômico de economia doméstica. Por consequência, os estudos sobre os espaços domésticos utilizavam como conceito-chave a "estratégia de sobrevivência".

Tal abordagem, restrita à análise econômica dos processos produtivos, pode ser utilizada sem perder de vista as outras variáveis necessárias ao desenvolvimento de atividades complexas.

Cientes da necessidade de utilizar racionalmente os recursos naturais, as sociedades rurais tradicionais têm mantido os seus padrões produtivos, não abrindo mão de técnicas seculares de utilização da terra para a transformação em produtos. Essas comunidades têm adotado com certa cautela inovações tecnológicas, já que podem colocar em risco suas diversas atividades cotidianas e consumir quantidades maiores de recursos naturais, fadando-as ao desaparecimento.

No mesmo sentido, os produtos da agricultura quilombola têm sido produzidos com a mesma diversidade de outrora, fato que tem despertado o interesse de outras sociedades em conhecer seus sistemas produtivos e, até mesmo, em consumir os seus diversos produtos.

Um fato interessante de ser abordado é que esses sistemas agrícolas não produzem unicamente alimento, tornando ainda mais sustentáveis tais sistemas. Os produtos culturais como 
rezas, danças e festas são cada vez mais responsáveis pela renda monetária das comunidades, pois preservam os padrões identitários e ambientais, capazes de perpetuar seu meio de vida.

Diante do exposto, ao serem observadas novas variáveis capazes de gerar desenvolvimento econômico, trata-se a seguir, em termos epistemológicos, da intervenção dos atores públicos no financiamento de políticas públicas de geração de trabalho e renda monetária.

\section{A AGRICULTURA QUILOMBOLA DE JUÇARAL DOS PRETOS/MA}

Juçaral dos Pretos é uma comunidade quilombola localizada no município de Presidente Juscelino/MA, sendo assim definida por conta dos primeiros moradores do local, que receberam a terra por meio de uma doação (herança) do antigo dono. Essa doação possui respaldo legal, pois está registrada através de escritura em cartório local. A comunidade possui cópia desse documento e faz parte de uma quantidade significativa das Terras de Pretos no estado do Maranhão.

Em Juçaral dos Pretos, durante o processo de observação participante, notou-se que o desenrolar das atividades econômicas evidenciam a profunda ligação com os recursos naturais e a natureza de uma forma geral, não havendo outra forma de produção que não esteja ligada diretamente à utilização desses recursos. Configura-se, assim, uma relação muito forte entre sociedade de camponeses e natureza viva, expressa em todos os termos e condições da vida cotidiana dessas famílias.

Essa assertiva respalda os conceitos de Santos (1976), que discute o espaço mediante a sua vinculação com o social e o cultural. Nesse caso específico, a relação com a natureza é a forma mais expressiva de manifestação cultural. Essa manifestação não se refere aos folguedos populares, mas diretamente à forma de viver, a partir dos meios encontrados pelas famílias de quilombolas no que tange à construção, reconstrução e utilização do espaço físico durante a labuta diária.

Essas relações comunitárias são extremamente fortes e estão vinculadas ao processo de comercialização dos 98 produtos, que variam pelas quantidades comercializadas e pelo clima (regime pluviométrico principalmente). O processo de comercialização forma um laço de fragilidade ou de pouca penetração no mercado de consumo de alimentos, principalmente pela falta de regularidade do fornecimento de produtos.

A oferta de produtos ao mercado é muito pequena e restrita ao excedente da produção destinada ao consumo das famílias. Não existe, portanto, uma produção destinada ao abastecimento das necessidades do mercado ou de programas destinados à compra da produção agrícola. Então, não é correto afirmar que existe produção comercializada.

Essa informação encontra sustentação por meio da observação de instrumentos e estruturas utilizados pelas famílias de Juçaral dos Pretos, os quais beneficiam a produção de farinha, principal atividade econômica desenvolvida no quilombo.

A produção comercializada pelos quilombolas de Juçaral dos Pretos é formada basicamente pelo excedente da produção agrícola destinada ao consumo alimentar das famílias. Dessa forma, todos os produtos comercializados possuem uma característica identitária muito forte, fazendo surgir a necessidade de separação dos conceitos de produto e de mercadoria.

A relação com o mercado acontece de forma inversa, ou seja, quando as outras sociedades de agricultores se aproximam do quilombo e percebem neste um potencial produtor de alimentos, encontram produtos responsáveis pela manutenção peculiar do meio de vida desse 
grupo social. Assim, as famílias, através de suas identidades, criam um mercado diferenciado, ou seja, existe a formação de um mercado de produtos que não é destinado ao mercado, fazendo com que apareça uma demanda sobre esses produtos.

Dialeticamente, essa relação é construída de fora para dentro da comunidade. Isso faz com que se constitua um processo de apropriação continuada, por parte de outras sociedades, culturas e tradições próprias de Juçaral dos Pretos. Esse processo diferenciado, ao contrário dos demais, fortalece os padrões tecnológicos, econômicos e, sobretudo, sociais da comunidade, além de todos os preceitos identitários. Assim, quando a farinha produzida no quilombo é consumida, ela é aceita por outras sociedades de agricultores a partir de um olhar interpretativo da realidade, adotado pelos quilombolas de Juçaral dos Pretos. Por isso, não existe um produto produzido destinado ao mercado.

O mercado ou a relação mercadológica surge por motivação externa. Muitas vezes, essas demandas de consumo dos seus produtos identitários são até rechaçadas pelos quilombolas de Juçaral dos Pretos, que preferem manter sua autonomia no processo de destinação do seu pequeno excedente produzido, sendo este utilizado para o fortalecimento das relações sociais internas.

A política de reconhecimento das comunidades de Juçaral dos Pretos como área quilombola é perfeitamente entendida e validada, pois, de forma peculiar, os produtos que são produzidos, destinam-se ao abastecimento das necessidades das famílias quilombolas e não aos mercados externos. A farinha de mandioca, principal produto comercializado, não passou por nenhum tipo de transformação para atender às demandas do mercado consumidor, mantendo as características ditadas pelo mercado interno. Ela continua sendo produzida em barracões de taipa, com uso de fornos de ferro aquecidos com lenha, retirada das capoeiras próximas do local do beneficiamento, caracterizando um sistema tradicional de produção.

A mandioca, após ser colhida e colocada em pubeiros (que são pequenas áreas cercadas de madeira e forradas com palha), vai fermentar por cinco dias, dentro de igarapés, até chegar ao ponto de ser descascada. O passo seguinte é ralar (triturar) as raízes fermentadas em catitús e espremê-las em tapiti, que são prensas ${ }^{3}$ utilizadas para secar a massa da mandioca. A massa é posteriormente peneirada para a retirada das caroeiras, ou seja, as partes das raízes da mandioca que não foram trituradas durante o processo de ralagem da raiz. As caroeiras são levadas ao forno para torrar.

Após torradas, as caroeiras são acondicionadas em cestos de palha de babaçu e cobertas com folhas de bananeira. Essas embalagens são denominadas de paneiros, unidade de medida utilizada pelos quilombolas que, em média, pesam cerca de 30 quilos. Os paneiros são posteriormente comercializados na própria comunidade.

O preço pago pelo produto tem variação sazonal, oscilando entre $\mathrm{R} \$ 3,00$ a $\mathrm{R} \$ 5,00$ por $\mathrm{kg}$, na época da safra. Em outras épocas de menor oferta do produto, o preço varia de $\mathrm{R} \$ 7,00 \mathrm{a}$ $\mathrm{R} \$ 10,00$.

Em Juçaral dos Pretos, o fazer farinha tem um contexto bem diferente do observado em Boa Vista dos Pinhos, comunidade rural distante aproximadamente $20 \mathrm{~km}$. Na primeira análise, foi observada uma tecnologia social sendo desenvolvida de forma inusitada, um processo organizativo ímpar que é capaz de gerar renda e desenvolvimento. Em Juçaral dos Pretos, o fazer farinha significa viver o quilombo, manter as práticas ancestrais, ou seja, preservar as matrizes culturais existentes que são desenvolvidas sem aporte externo de recursos, o que torna o pro-

${ }^{3}$ Feitas de palha de guarimã.

PRACS: Revista Eletrônica de Humanidades do Curso de Ciências Sociais da UNIFAP 
cesso sustentável sob todas as análises.

A tradição alimentar do quilombo também garante a essa comunidade a possibilidade de ampliação da renda por meio do plantel de aves, dentre elas galinhas caipiras, frangos, patos, perus e marrecos. Esses animais são criados de maneira extensiva, nos fundos de quintais denominados terreiros, e são alimentados pelo milho produzido na roça, juntamente com as cascas da mandioca que resultam do processo de produção de farinha.

A produção de aves, embora em pequena escala, é responsável por um significativo percentual da renda monetária das famílias de agricultores, principalmente quando é observado o valor individual de comercialização de cada unidade animal. Esse valor é calculado e prontamente pago pelos atravessadores, em virtude da grande demanda externa pelo produto, em função de tradições e costumes locais.

Geralmente, os aniversários são comemorados com uma boa galinha caipira, razão da relativa facilidade no processo de comercialização, constituindo-se em um importante elemento de desenvolvimento. Um fato peculiar nesse sistema produtivo é o tempo necessário à formação da ave para a comercialização. Em um sistema moderno, que é subsidiado por uma escala de comercialização, esse tempo é, em média, de 60 dias e, para os quilombolas de Juçaral dos Pretos, é de 365 dias.

Os suínos também têm importância na renda monetária das famílias do quilombo. A partir da forma tradicional de criação, os porcos são criados soltos, o que permite a ampliação na oferta do produto. Os animais são criados no fundo do quintal das famílias de agricultores quilombolas. Essa prática também é responsável por sérios problemas sociais vivenciados no quilombo, uma vez que existem muitos casos de brigas de vizinhos e agressões pessoais provocados pelas invasões de porcos nas roças de mandioca, que resulta no completo extravio da produção.

Embora pareça que a comunidade Juçaral dos Pretos não produza renda monetária, isso não é verdade. Nesse sentido, esta pesquisa mostra que as tradições culturais são responsáveis pela economia local, inclusive pela geração de renda monetária, que é obtida pelo pequeno excedente de produção e pelos recursos arrecadados nas festas e festejo. Esses meios constituem hoje a maior fonte de renda dessa comunidade.

O modelo autóctone tradicional, categorizado como o principal elemento da pobreza do local, é mostrado e trabalhado pelos quilombolas de Juçaral como o responsável pela renda, quebrando um paradigma já cristalizado pelas ciências conservadoras. Dessa forma, é possível traçar uma nova fórmula que determine a renda tradicional das comunidades tradicionais. Nessa fórmula os fatores de maior impacto econômico são a preservação da identidade social e a preservação dos recursos naturais.

Esses elementos juntos se transfiguram e dão origem a um enorme potencial de geração de renda, capaz de incluir economicamente as sociedades tradicionais sem, contudo, abrir mão de sua autonomia produtiva e perder seus referenciais identitários.

Acredita-se ser necessário frisar que as sociedades tradicionais são constituídas, principalmente, pela necessidade de manutenção desses referenciais. No momento em que estes são destruídos, o processo de resiliência social camponesa toma outros rumos, comumente distantes daqueles já utilizados. Esse processo é incapaz de produzir segurança social para que sejam traçadas alternativas que garantam as mínimas condições de dignidade, em especial para quem foi desapropriado de sua história. O resultado é a geração de um passivo impossível de ser mensurado sobre todos os aspectos analíticos. 
Em consequência, pode-se observar diariamente nas manchetes dos jornais e de outros veículos de comunicação a narração sobre a fuga em massa das sociedades rurais para os centros urbanos, além de todos os problemas causados pelo êxodo.

No quilombo de Juçaral dos Pretos, a produção agrícola é muito mais diversa, o que demonstra profundo apego à cultura alimentar e peculiar desse grupo. Esse é um forte fator de diferenciação social. A autonomia produtiva é muito forte em função da manutenção dos hábitos culturais, que sofrem pouca influência do meio externo em termos de novas variedades e espécies vegetais. Esses hábitos estão refletidos nesta discussão e se caracterizam pela importância de sua manutenção.

O comércio local é formado basicamente de uma pequena cantina, onde são oferecidos produtos que não são produzidos pelas comunidades locais, sem qualquer apego ao consumo. Dentre esses produtos são comercializados o sabão, o macarrão, óleo de soja, refrigerantes e biscoitos, elementos que começam a impactar na realidade local e a aparecer na dieta dessas famílias, substituindo a alimentação tradicional.

Nesse comércio também são vendidos o arroz, o feijão e o milho, que são produzidos internamente, além de bebidas alcoólicas, que são adquiridas por meio da renda monetária das famílias. Essa renda é obtida por meio dos processos de venda da produção, venda de mão de obra e, recentemente, pelos programas de transferência de renda e seguridade social, destinados às famílias de quilombolas. No entanto, a realidade de compra dos produtos básicos ainda está bastante distante da comunidade.

Dentro do universo amostral, aproximadamente 7 famílias pesquisadas (70\%) ainda praticam o cultivo do arroz, que se configura como um importante elemento na composição da renda dos agricultores, uma vez que o mesmo tem uma importância cultural reconhecida. O milho também é uma cultura fundamental na manutenção da identidade dos quilombolas. É cultivado por $60 \%$ dos agricultores do quilombo, ou seja, 6 famílias, e é utilizado para subsidiar a criação de porcos, atividade desenvolvida por 3 entre os 10 agricultores, e de galinhas caipiras, por 30\% das famílias. A criação de galinha caipira é para o consumo da própria comunidade.

No contexto de consumo dos produtos agrícolas, a farinha, mais uma vez, assume o protagonismo do processo produtivo, uma vez que 100\% das famílias pesquisadas produzem para consumo próprio. Esse é um fato marcante, pois a produção de farinha envolve uma quantidade expressiva de elementos e percepções por parte dos agricultores, sendo esta mais forte no quilombo de Juçaral dos Pretos.

Em função da importância da farinha para a economia local, existe uma grande preocupação com a preservação das fontes de água, pois são nesses balneários onde ocorre o processo de fermentação da raiz de mandioca.

A manga aparece em um contexto muito parecido com o caju, sendo que dentro de um universo de 10 famílias pesquisadas, 6 famílias (60\%) declaram que a manga é um componente complementar do cardápio e da geração de renda.

Em um contexto geral, começam a aparecer agricultores que buscam outras atividades produtivas fora das práticas tradicionais, como é o caso de uma família que desenvolve a criação de bovinos destinada ao corte, para o consumo da comunidade. Entretanto, essa atividade não se configura apenas para autoconsumo, pois gera excedente de produção para o mercado.

A produção de ovos na comunidade é decorrente do processo de reprodução das galinhas, destinadas ao abate. Mesmo assim, ainda são retiradas algumas dúzias para a complementação 
do cardápio diário, ou seja, para o consumo alimentar das famílias de agricultores. Portanto, não existe uma produção de ovos destinada somente à alimentação dos quilombolas.

O Quadro 1 apresenta os produtos produzidos pela comunidade quilombola de Juçaral dos Pretos/MA, conforme a quantidade de famílias que residem no local.

Quadro1 - Produtos produzidos e consumidos na comunidade quilombola de Juçaral dos Pretos, município de Presidente Juscelino/MA

\begin{tabular}{|c|c|c|c|c|c|c|c|c|c|c|c|}
\hline Famílias & $\begin{array}{c}\text { Arroz } \\
(\mathrm{kg})\end{array}$ & $\begin{array}{c}\text { Milho } \\
(\mathrm{kg})\end{array}$ & $\begin{array}{c}\text { Feijão } \\
(\mathrm{kg})\end{array}$ & $\begin{array}{c}\text { Farinha } \\
(\mathrm{kg})\end{array}$ & $\begin{array}{c}\text { Manga } \\
(\mathrm{kg})\end{array}$ & $\begin{array}{c}\text { Cajú } \\
(\mathrm{kg})\end{array}$ & $\begin{array}{c}\text { Juçara } \\
(\mathrm{L})\end{array}$ & $\begin{array}{c}\text { Bovinos } \\
(\mathrm{kg})\end{array}$ & $\begin{array}{c}\text { Suínos } \\
(\mathrm{kg})\end{array}$ & $\begin{array}{c}\text { Aves } \\
(\mathrm{kg})\end{array}$ & $\begin{array}{c}\text { Ovos } \\
(\mathrm{dz})\end{array}$ \\
\hline Família 1 & 720 & & & 4.200 & & 150 & 280 & & & 300 & 67,5 \\
\hline Família 2 & 900 & 1.800 & & 4.900 & 100 & 10 & 700 & & & 720 & \\
\hline Família 3 & 450 & 1.500 & & 4.200 & 10 & 10 & 70 & & & 400 & 45 \\
\hline Família 4 & 30 & 30 & & 4.200 & 10 & 10 & 280 & & & & \\
\hline Família 5 & & & & 4.200 & 10 & & & & 2.160 & 600 & \\
\hline Família 6 & 900 & 600 & 550 & 4.200 & & & & & & 200 & 90 \\
\hline Família 7 & & & & 8.400 & & & & & 1.200 & 200 & \\
\hline Família 8 & 150 & 150 & & 4.200 & 10 & 10 & 525 & & & 240 & \\
\hline Família 9 & 360 & 720 & & 2.100 & 10 & 10 & 210 & 1.200 & & & \\
\hline Família 10 & & & & 1.050 & 10 & & & & 240 & 100 & 900 \\
\hline
\end{tabular}

Fonte: Pesquisa de Campo, 2015

\section{A RENDA FINAL DA COMUNIDADE DE JUÇARAL DOS PRETOS}

No quilombo de Juçaral dos Pretos existe uma uniformidade bem maior na variação da renda final, compreendida em um intervalo de $\mathrm{R} \$ 10.830,00$ a $\mathrm{R} \$ 24.260,00$ por família pesquisada, ficando concentrada na faixa de $\mathrm{R} \$ 15.000,00$, demostrando uma pequena desigualdade. A maior parte da renda produzida no quilombo de Juçaral dos Pretos é destinada ao abastecimento das necessidades das famílias. Essa renda também provém da venda da força de trabalho e, por último, da venda de produtos da agricultura e do beneficiamento da produção.

A maior renda é obtida pela família, que mantém as atividades de venda de farinha muito ativas, não se restringindo apenas ao comércio do que é produzido, mas também desenvolvendo atividade de atravessador da produção agrícola.

A menor renda também vem de famílias que desenvolvem atividades de comercialização de farinha, mas o diferencial está no fato de que não é observada a presença de atravessadores. Nesse caso, a farinha é comercializada na própria comunidade, para quem eventualmente tenha interesse em adquirir o produto, caracterizando um sistema incompleto e desorganizado do ponto de vista do desenvolvimento.

Assim, fica clara a necessidade de serem estabelecidas políticas de acesso aos mercados externos, cuja finalidade é a ampliação da geração de renda monetária na comunidade de Juçaral dos Pretos. A desorganização da comercialização observada é proveniente do não estabelecimento de um fluxo constante de contato entre produtores e consumidores, acentuada pela distância entre o local de produção e o local de maior demanda de consumo, fator que aumenta o custo final do consumidor.

Diante do exposto, pode-se caracterizar a renda final da comunidade de Juçaral dos Pretos como uma forma de expressar o nível interno de organização da produção e comercialização da produção total, influenciada diretamente por uma fortíssima valorização da cultura local. Essa renda é pouco variável, pois os fluxos produtivos internos não sofrem pressões diretas dos mercados econômicos, fazendo com que os processos de diferenciação social não tenham 
força.

A diferenciação social também é garantida pelos processos produtivos, mas a tradição no ato de produzir é determinante e gera um status diferenciado. Esse fato não é observado fora das sociedades tradicionais.

\section{REFERÊNCIAS}

BRUMER, Anita; SANTOS, José Vicente Tavares dos. Estudos agrários no Brasil: modernização, violência e lutas sociais (desenvolvimento e limites da Sociologia Rural no final do Século XX). Revista NERA, Presidente Prudente, v. 9, n. 9, p. 49-72, jul./dez. 2006.

ELLIS, Frank. Rural Livelihood and Diversification in Developing Countries. Oxford: University Press, July 2000.

GARCIA, Dolores Dominguez. Desenvolvimento rural sustentável: uma perspectiva agroecológica. Revista Agroecologia e Desenvolvimento Rural Sustentável, Porto Alegre, v. 2, n. 2, p. 17-26, 2001.

HAAN, L and ZOOMERS, A. Exploring the frontier of livelihoods research. Development and Change. 36 (1): 27-47. 2005.

HOLANDA, Sérgio Buarque de; EULÁLIO, Alexandre; RIBEIRO, Leo Gilson. Raízes do Brasil. São Paulo: Companhia das Letras, 1995.

MAZOYER, Marcel; ROUDART, Laurence. Histórias das agriculturas no mundo: do neolítico à crise contemporânea. Tradução: Cláudia F. Falluh Balduino Ferreira. São Paulo: Editora UNESP, 2010.

MORIN, Edgar. Os sete saberes necessários à educação do futuro. Tradução: Catarina Eleonora F. da Silva e Jeanne Sawaya; revisão técnica de Edgar de Assis Carvalho. 9.ed. São Paulo: Cortez, Brasília: UNESCO, 2004. 118p.

PERONDI, Miguel Angelo. Diversificação dos meios de vida e mercantilização da agricultura familiar.2007. 237f. Tese (Doutorado em Desenvolvimento Rural) - Universidade Federal do Rio Grande do Sul, Porto Alegre, 2007.

SANTOS, Milton. A natureza do espaço: técnica e tempo, razão e emoção. 4. ed. São Paulo: Editora da Universidade de São Paulo, 2002.

SANTOS, Milton. Articulation of modes of production and the two circuits of urban economy: wholesalers in Lima, Peru. Pacific Viewpoint, v. 17, n.1, p. 23-36, 1976.

SODRÉ, Federica Natasha Ganança Abreu dos; FREITAS, Rodrigo Randow de; REZENDE, Vera Lúcia Ferreira Motta.Um panorama da aqüicultura como alternativa sócioeconômica as comunidades tradicionais. Revista Brasileira de Agroecologia, v.3, n. 3, p. 1323, dez. 2008.

SOUSA, Jessie Jane Vieira de. Acomodações recíprocas: a igreja católica e o poder temporal na argentina e no brasil. Passagens -Revista Internacional de História Política e Cultura Jurídica, Rio de Janeiro, v.1, n. 2, p. 50-64, 2009. 